\title{
ASPECTOS DA TEOLOGIA POLÍTICA, MÍSTICA E FEMINISTA DE DOROTHEE SÖLLE: RELAÇÕES COM O MOVIMENTO DOS TRABALHADORES RURAIS SEM TERRA (MST) E A EDUCAÇÃO POPULAR $^{1}$
}

\section{Aspects of the political, mystical and feminist theology by Dorothee Sölle: relations with the Landless Workers Movement (MST) and popular education}

\author{
Paulo Alfredo Schönardie ${ }^{2}$ \\ Claudete Beise Ulrich ${ }^{3}$
}

\begin{abstract}
Resumo:
O propósito central deste trabalho visa apresentar os aspectos da teologia política, mística e feminista de Dorothee Sölle e suas relações com o Movimento dos Trabalhadores Rurais Sem Terra e a educação popular. Sölle foi uma teóloga muito atuante, comprometida com os desafios sociais e políticos de seu tempo histórico. A razão do desenvolvimento da reflexão está em evidenciar a construção teológica prática e teórica ainda pouco explorada de Sölle e a sua possível contribuição com a reflexão e práxis teológica e social na atualidade. Entendemos a tessitura teológico-social apresentada e vivida por Sölle como possibilidade humanizadora. O texto metodologicamente está baseado em análises bibliográficas, apresentando primeiro aspectos biográficos de Dorothe Sölle, seguindo reflexão sobre sua relação com o Movimento dos Trabalhadores Rurais Sem Terra e finalmente apresentando a teologia política, mística e feminista como processo educativo popular. Conclusivamente é possível inferir que a práxis, a ação e a reflexão vivenciadas por Sölle estão na base da educação, da teologia, da sociedade.
\end{abstract}

Palavras-chave: teologia política, mística, feminista, Dorothee Sölle, Movimento dos Trabalhadores Rurais Sem Terra, educação popular

\section{Abstract:}

The main purpose of this paper is to present the aspects of the political, mystical and feminist theology from Dorothee Sölle and its relations with the Landless Workers Movement (MST) and the popular education. Sölle was a very active theologian, engaged with the social and political challenges of her historical time. The reason behind the development of this

1 Submetido em: 13.06.2020. Aceito em: 21.09.2020.

2 Pós-Doutor em Educação. Doutor em Ciências Econômicas e Sociais pela Universidade de Hamburgo na Alemanha. Mestre em Educação nas Ciências e Licenciado em História pela Universidade Regional do Noroeste do Estado do Rio Grande do Sul - UNIJUÍ, RS. Contato: pschonardie@gmail.com

3 Pós-Doutoranda em Educação pela UFES, ES. Pós-Doutora em História pela UFSC, SC. Doutora e Mestre em Teologia pela Faculdades EST, RS. Graduada em Teologia e Licenciada em Pedagogia. Professora na Faculdade Unida de Vitória, ES. Contato: claudete@fuv.edu.br

Protestantismo em Revista | São Leopoldo | v. 46, n. 01 | p. 80-97| Jan./jun. 2020

Disponível em: <http://periodicos.est.edu.br/index.php/nepp> 
reflection is to evidence the theoretical and practical theological construction still little explored of Sölle and its possible contribuition with today's reflection and theological-social práxis. It is understood the theological-social context presented and lived by Sölle as a humanizing possibility. The text is methodologically based of bibliographic analyzes, presenting first the bibliographical aspects of Dorothee Sötte, followed by a reflection about its relation with the Landless Workers Movement and then finally presenting the political, mystical and feminist theology as a popular educational process. Conclusively, it is possible to infer that the práxis, the action and the reflection experienced by Sölle are in the grounds of education, theology and Society.

Key words: mystical, feminist, political theology, Dorothee Sölle, Landless Rural Workers Movement, popular education.

\section{Introdução}

Em 2013, o autor e a autora deste artigo se encontravam em Hamburgo, Alemanha. Paulo realizando o seu doutorado na Universidade de Hamburgo. Claudete trabalhando na Academia de Missão, instituição ligada à Faculdade de Teologia Protestante da Universidade de Hamburgo. Claudete, juntamente, com a Dra. Uta Andrée, organizaram por ocasião do 10 ano do falecimento da teóloga Dorothee Sölle um seminário com o título Inspiração para uma teologia da vida. ${ }^{4}$ Claudete então, convidou Paulo para fazer uma palestra, relacionando a teologia política mística de Sölle com o Movimento dos Trabalhadores Rurais Sem Terra e a educação popular. ${ }^{5}$ Assim, este texto foi construído a quatro mãos a partir do que lemos, ouvimos, falamos e aprendemos em conjunto sobre esta mulher fantástica, grande teóloga, engajada pela justiça social e contra o cristofascismo. Ela faleceu no início do século XXI.

O protesto e a ação de mulheres e homens, embasadas e embasados em valores cristãos, perante as injustiças sociais de suas épocas, lançaram e continuam lançando centelhas de resistência, muitas vezes às margens do possível. De acordo com Edla Eggert, construindo uma teologia das margens ${ }^{6}$. Entendemos que, desta forma, se amplia a envergadura política contextual da teologia, em uma realidade social na maioria das vezes adversa, por isso mesmo, fazendo parte de um movimento histórico e atual de constante reforma e transformação. A reflexão teológica não é neutra e sempre necessita estar situada historicamente.

4 ULRICH, Claudete Beise; ANDREE, Uta. (Org.) (Theologische Impulse der Missionsakademie - Tima). Inspiration für eine Theologie des Lebens. Die Theologie von Dorothee Sölle im Licht der Befreiungstheologie. Hamburg: Missionsakademie an der Universität Hamburg, 2014.

5 Palestra publicada por SCHÖNARDIE, P. A. Die Landlosenbewegung (MST) Brasiliens und die politische Theologie von Dorothee Sölle. In: ULRICH, Claudete Beise; ANDREE, Uta. (Org.). (Theologische Impulse der Missionsakademie - Tima). Inspiration für eine Theologie des Lebens. Die Theologie von Dorothee Sölle im Licht der Befreiungstheologie. Hamburg: Missionsakademie an der Universität Hamburg, 2014, p. 87-92.

6 EGGERT, Edla. Educação popular e teologia das margens. São Leopoldo: Sinodal, 2003.

Protestantismo em Revista | São Leopoldo | v. 46, n. 01 | p. 80-97| Jan./jun. 2020

Disponível em: <http://periodicos.est.edu.br/index.php/nepp> 
Neste sentido, o acontecimento histórico protagonizado por Martim Lutero, em 1517, ao questionar injustiças em seu tempo, pregando as 95 teses para serem debatidas por sua comunidade em Wittenberg na Alemanha, é sem dúvida um dos grandes marcos da Reforma Protestante. Quatro das 95 teses afixadas por Lutero, apontam para o papel primordial do Evangelho: os pobres. As teses 43, 45, 59 e 86 afirmam

Tese 43: "Deve-se ensinar aos cristãos que, dando ao pobre ou emprestando ao necessitado, procedem melhor do que se comprassem indulgências":

Tese 45: "Deve-se ensinar aos cristãos que quem vê um pobre e o negligencia para gastar com indulgências obtém para si não as indulgências do papa, mas a ira de Deus".

Tese 59: "S. Lourenço disse que os pobres da Igreja são os tesouros da mesma, empregando, no entanto, a palavra como era usada em sua época".

Tese 86: "Por que o papa, cuja fortuna hoje é maior que a dos mais ricos Crassos, não constrói com seu próprio dinheiro ao menos esta uma Basílica de São Pedro, ao invés de fazê-lo com o dinheiro dos pobres fiéis"? ${ }^{7}$

Segundo Ulrich e Brakemeier, todo o sistema sócio religioso que se beneficiava da pobreza é profundamente questionado e criticado a partir da teologia da justificação por graça e fé. Podemos dizer que a teologia do movimento da reforma afirmou os pobres como sujeitos de direitos, libertando-os das obras de caridade. As obras de caridade, que se faziam em benefício dos pobres, tinham somente o objetivo de aliviar a própria consciência e de garantir um lugar no céu. O movimento da reforma, realizado por homens e mulheres, afirma a necessidade de mudanças radicais na sociedade, na política, na economia e na ética religiosa. Desloca-se o foco teológico: de ações voltadas para alcançar o céu, através do sistema das indulgências, volta-se para a realidade social das pessoas, dos/as pobres e dos/as necessitados/as. ${ }^{8}$

Importante deixar claro que, o protesto e ação de Lutero não é um acontecimento isolado. É oriundo da conjuntura histórica e da situação de premência vivida por grande parte da população em sua época. Por isso mesmo, o início do século XVI foi um período de profícuos questionamentos, embasados em valores cristãos, a partir das muitas margens, como também atesta Friedrich Engels, quando historiciza os movimentos protestantes reformadores de Martinho Lutero e Thomas Müntzer. ${ }^{9}$ De uma forma bastante

7 LUTERO, Martinho. Explicações do Debate sobre o valor das indulgências. In: LUTERO, Martinho. Obras Selecionadas. Os primórdios escritos de 1517 a 1519, Vol. 1, São Leopoldo: Sinodal; Porto Alegre: Concórdia, 1987, p. 152, p. 153, p. 171; p. 187.

8 ULRICH, Claudete Beise; BRAKEMEIER, Ruthild. Mulheres reformadoras fazendo Diaconia e Direitos. In: KUSS, Cibele (Org.). Fé, justiça de gênero e incidência pública: 500 anos da reforma e diaconia transformadora. Porto Alegre: Fundação Luterana de Diaconia, 2017, p. 12-13.

9 WIRTH, Lauri Emilio. Antecedentes Populares da Reforma Protestante: Para entender os doze artigos do Campesinato da Suábia. In: ZWETSCH, Roberto (Org.). Resgatando a Radicalidade da Reforma Protestante (1517-2017). São Leopoldo: Centro de Estudos Bíblicos - CEBI, 2019, p. 104-112. "O debate em torno dos Doze Artigos do Campesinato da Suábia na verdade, instiga um debate atual, necessário e urgente. Trata-se da permanente tensão entre o universo utópico que alimenta nossos sonhos de vida em sociedade e a plausibilidade histórica desta sociedade imaginada. Neste sentido, Thomas Müntzer e os camponeses rebelados exigiam que o imaginário religioso de uma sociedade fraterna, justa e igualitária fosse concretizado na prática, já que toda a sociedade se dizia cristã [...]. Neste sentido, Thomas Müntzer e os camponeses viam a luta armada como uma forma legítima, não só de instituir um mundo mais justo, mas de proclamar o

Protestantismo em Revista | São Leopoldo | v. 46, n. 01 | p. 80-97| Jan./jun. 2020

Disponível em: <http://periodicos.est.edu.br/index.php/nepp> 
ampla, Engels destaca que os movimentos reformadores queriam que "a igualdade dos filhos (sic) de Deus deveria traduzir-se pela igualdade dos cidadãos (sic) e até pela dos seus bens". ${ }^{10}$ É isto que se percebe nos Doze Artigos do Campesinato da Suábia $(1525)^{11}$, fundamentados na Palavra de Deus, expressam as reivindicações dos/as camponeses na luta por direitos em seu tempo histórico.

Com cinco séculos percorridos desde a conjuntura inicial das reformas protestantes, seus adeptos foram crescendo, mas os problemas sociais não foram extintos. Em diferentes situações inclusive, se agravaram. Obviamente que a sociedade se manteve em movimento nos diferentes períodos históricos. Da mesma forma, o ideário e a prática da reforma cristã também continuaram se movimentando e se transformando.

Desta forma, também Dorothee Sölle desenvolveu sua reflexão teológica de forma radical, profética e incondicional. ${ }^{12}$ Ela frequentemente lembrava em suas palestras e escritos a inspiradora teóloga mística Teresa de Ávila: "Deus não tem outras mãos, a não a ser as nossas". ${ }^{13}$ As suas palavras representam um desafio, um convite para a atuação social. Perceber e ouvir o "grito silencioso" dos oprimidos e excluídos em nosso mundo, significa tornar-se um/a com eles/as. ${ }^{14}$ Ela praticava uma teologia em que, por um lado, via a origem da fé no engajamento político e por outro lado, tinha neste engajamento político a base para a sua vida. Ela organizava sua ação cotidiana, a partir das necessidades políticas dos excluídos sociais. ${ }^{15}$ Ainda de acordo com a percepção de Schönardie, este seu movimento de fé e ação política fez dela uma revolucionária, ao mesmo tempo em que indicava novos caminhos para os grupos sociais envolvidos em resistência e para a própria Igreja como instituição. ${ }^{16}$ Entendemos Dorothee Sölle como uma teóloga ativa e que não se calou em seu tempo histórico. Ela se engajou profeticamente pelas causas sociais, pelos/as pobres e explorados/as

Evangelho. Lutero, por seu turno, entendia que guerras e revoluções sempre ocorreram na história, mas não admita que elas pudessem ser legitimadas pela fé do evangelho. Entendia também que o uso da violência era monopólio das autoridades instituídas, ação exclusiva dessas autoridades, com o que se colocou francamente contra os camponeses rebelados." (p. 111-112).

10 ENGELS, Friedrich. As guerras camponesas na Alemanha. Lisboa; São Paulo: Editorial Presença; Martins Fontes, 1975, p. 4.

11 OS DOZE ARTIGOS DO CAMPESINATO DA SUÁBIA (1525). Traduzido do alemão por WIRTH, Lauri E. a partir da versão publicada em OBERMANN, Heiko A. (Comp.). Die Kirche im Zeitalter der Reformation: Kirchen-und Theologiegeschichte in Quellen, Band 3, 2 Aufl. Neukirchen-Vluyn, 1985, documento no 64, p. 127-129. In: ZWETSCH, Roberto (Org.). Resgatando a Radicalidade da Reforma Protestante (1517-2017). São Leopoldo: Centro de Estudos Bíblicos - CEBI, 2019, p. 98-103.

12 WIND, Renate. Grenzenlos glücklich - absolut furchtlos - immer in Schwierigkeiten. München: Gütersloh, 2013, p. 6.

13 SÖLLE, Dorothee. Mystik und Widerstand: „Du stilles Geschrei“. Mit einer Einleitung von Fulbert Steffensky. Freiburg im Breisgau, 2014, p. 361.

14 SÖLLE, 2014, p. 361.

15 SCHÖNARDIE, Paulo Alfredo. Die Landlosenbewegung (MST) Brasiliens und die politische Theologie von Dorothee Sölle. In: ULRICH, Claudete Beise; ANDREE, Uta.(Org.) (Theologische Impulse der Missionsakademie - Tima). Inspiration für eine Theologie des Lebens. Die Theologie von Dorothee Sölle im Licht der Befreiungstheologie. Hamburg: Missionsakademie an der Universität Hamburg, 2014, p. 87.

16 SCHÖRNARDIE, 2014, p. 87.

Protestantismo em Revista | São Leopoldo | v. 46, n. 01 | p. 80-97| Jan./jun. 2020

Disponível em: <http://periodicos.est.edu.br/index.php/nepp> 
sendo uma protagonista da teologia política ${ }^{17}$, juntamente com Jürgen Moltmann ${ }^{18}$ e Johan Baptist Metz ${ }^{19}$.

Os movimentos reformadores como os de Lutero ${ }^{20}$, de Müntzer, entre outros, tinham forte ligação com a difícil realidade do campesinato. Em sua base estava a questão da terra, como já é percebido na afirmação de Engels acima apresentada, em que vê a terra como um bem a ser partilhado. Da mesma forma, Dorothee Sölle, construiu sua prática e teoria teológica a partir da luta pela terra protagonizada por camponesas e camponeses, numa conjuntura em que estes e estas se organizam no Movimento dos Trabalhadores Rurais Sem Terra (MST). Neste sentido, a teóloga, a partir dos anos 70, se aproximou da teologia da libertação. Numa nota de rodapé Helmuth Renders afirma: "Sölle substituiu a descrição da

17 SATHLER-ROSA, Ronaldo. Religiões, contexto e política: uma aproximação teológico-cultural. E-legis, n. 13, p. 7-20, 2014. Disponível em: <e-legis.camara.leg.br> e-legis > article > download>. Acesso em: 22 abr. 2020. "Apesar de diferenças em suas elaborações teológicas tanto Metz, como Moltmann e Sölle convergem em duas posições: a teologia política é considerada uma hermenêutica e a teologia política é uma crítica à lgreja e à própria teologia. A crítica à lgreja e à teologia centraliza-se, em especial, na privatização da fé cristã. É criticado o alheamento da Igreja e de seus seguidores com relação aos problemas que atingem a sociedade como um todo".

18 O teólogo Jürgen Moltmann está com 94 anos e reside em Tübingen, na Alemanha. É autor de inúmeros livros e artigos. Concordamos com KUZMA, Cesar. O teólogo Jürgen Moltmann e o seu caminhar teológico realizado na esperança. Acenos teo-biográficos. Atualidade Teológica, Ano XVII n. 43, p. 15-38, 2013. Que a obra Teologia da Esperança se soma a todas as outras teologias desenvolvidas pelo autor (política, ecológica, pneumatológica). A Esperança ativa é o grande motor teológico de Moltmann. MOLTMANN, Jürgen. Teologia da esperança: estudos sobre os fundamentos e as consequências de uma escatologia cristã. 3 ed. São Paulo: Teológica, Loyola, 2005.

19 O teólogo Johann Baptist Metz faleceu em 2019. Ele foi o fundador da nova teologia política. METZ, J. B. Teologia Política. Trad. Luis Alberto De Boni. Porto Alegre: Escola Superior de Teologia São Lourenço de Brindes; Caxias do Sul: Universidade de Caxias do Sul, 1976. Assim como Moltmann e Sölle, a reflexão teológica de Metz deita suas raízes reflexivas na experiência incompreensível do sofrimento de Auschwitz. A memória é fundamental para que Auschwitz não mais se repita. Veja também GONÇALVES, Paulo Sérgio Lopes. Nova Teologia Política: memoria passional e mística de olhos abertos. Cultura Teológica, n. 93, p. 272301, 2019. Disponível em: <https://revistas.pucsp.br/culturateo/article/view/rct.i93.42770>. Acesso em: 20 maio 2020.

20 É fato que o movimento da Reforma Protestante protagonizada por Lutero tinha fortes ligações com os/as camponeses. A sociedade da época era ainda predominantemente camponesa. Mas também é preciso registrar que essas ligações não eram pacíficas. Para garantir seu pensamento reformador Lutero foi direcionado a se aliar a determinados grupos (príncipes/nobres) que também possuíam em suas fileiras camponesas e camponeses. Já a relação com os camponeses aliados a grupos contrários não foi das melhores. Consequentemente os conflitos surgidos para garantir a efetivação da reforma vitimaram muitos/as, e como a sociedade era basicamente camponesa, obviamente a maior quantidade de vítimas foi de camponeses e camponesas. As posições de Lutero, mesmo que historicamente localizadas, são contraditórias e também raivosas, necessitando de uma profunda análise crítica. Neste sentido, recomendamos a leitura LUTERO, Martinho. Exortação à paz: Resposta aos Doze Artigos do Campesinato da Suábia 1525. In: LUTERO, Martinho. Obras selecionadas. São Leopoldo: Sinodal, Porto Alegre: Concórdia, 1996. v. 6, p. 304-329. Vejam o texto adendo ao anterior indicado, extremamente agressivo em relação aos camponeses LUTERO, Martinho. Exortação à paz: Resposta aos Doze Artigos do Campesinato da Suábia 1525. Adendo: Contra as Hordas Sateadoras e Assassinas dos Camponeses 1525. In: LUTERO, Martinho. Obras selecionadas. São Leopoldo: Sinodal, Porto Alegre: Concórdia, 1996. v. 6, p. 330-336.

Protestantismo em Revista | São Leopoldo | v. 46, n. 01 | p. 80-97| Jan./jun. 2020

Disponível em: <http://periodicos.est.edu.br/index.php/nepp> 
sua teologia como teologia política pela designação Teologia de Libertação ao redor de 1975." 21

Dorothee Sölle se encontra, em nosso entender, na continuidade daquelas e daqueles que buscaram transformações sociais e políticas, a partir de uma reflexão contextual e crítica da fé cristã. Ela é uma das mulheres teólogas místicas do movimento da reforma contemporânea. ${ }^{22}$ Apresentamos, na sequência alguns aspectos da biografia de vida de Dorothee Sölle, o seu entrelaçamento reflexivo com os movimentos sociais e consequentemente com o Movimento dos Trabalhadores Rurais Sem Terra (MST), ou seja, apresentamos a sociedade em que as lutas e reformas se dão histórica e hodiernamente.

A realidade de vida e a consequente vivência da fé cristã se apresentam como um processo de educação popular pela práxis ${ }^{23}$. Tem-se por um lado uma construção educativa, e por outro, a difusão das vivências pelo mesmo processo educativo popular. Assim, se faz mister também tematizar a teologia política/da libertação como processo educativo popular que, por sua vez dá vida e continuidade histórica ao movimento da reforma que busca no tempo presente, transformações. Por fim, retomaremos a perspectiva da teologia política/da libertação de Sölle em sua relação com os processos de reforma da Igreja, estes vivenciados a partir dos contextos sociais e dos processos educativos que realimentam a tessitura social.

\section{Dorothee Sölle: alguns aspectos biográficos}

Dorothee Sölle nasceu em 30 de setembro de 1929, em Köln (Colônia) e faleceu em 27 de abril de 2003 em Göppingen, na Alemanha. ${ }^{24}$ Ela foi professora, escritora, pesquisadora, palestrante, teóloga, luterana. Quando terminou o colegial (ensino médio), estudou inicialmente filosofia e filologia clássica em Colônia. Mudou de curso e dedicou-se aos estudos da Teologia Protestante e Estudos Alemães em Freiburg e Göttingen, e obteve o seu título de doutora em filosofia, em 1954. De 1954 a 1960, Sölle foi professora de uma escola secundária para meninas em Colônia-Mülheim. Trabalhou como freelancer para estações de rádio e revistas. Em 1962, tornou-se assistente no Instituto Filosófico da Universidade Técnica de Rheinisch-Westfälische em Aachen e, em 1964, atuou como orientadora no serviço universitário estudantil no Instituto Germânico da Universidade de Colônia. Também realizou nesta Universidade, a sua habilitação para atuar como professora universitária. Na tese para habilitação, ela trabalhou a relação entre teologia e poesia, terminando-a, em 1971.

21 RENDERS, Helmut. Um testemunho de esperança como summa theologicae de uma vida. Resenha do livro MOLTMANN, Jürgen. Vida, esperança e justiça: um testamento teológico para a América Latina. Tradução: Haroldo Reimer e Levy da Costa Bastos. São Bernardo do Campo, SP: Editeo, 2008. Estudos de Religião, v. 23, n. 36, citação n. 13, p. 280, 2009. Disponível em: <https://www.metodista.br/revistas/revistasims/index.php/ER/issue/view/75>. Acesso em: 20 mai. 2020.

22 ULRICH, Claudete Beise; DALFERTH, Heloisa Gralow. (Org.) Mulheres no Movimento da Reforma. São Leopoldo: Sinodal, 2017.

23 FREIRE, Paulo. Pedagogia do oprimido. Rio de Janeiro: Paz e Terra, 1987, p. 53. "A práxis se constitui a razão nova da consciência oprimida e que a revolução, que inaugura o momento histórico desta razão, não pode encontrar viabilidade fora dos níveis de consciência oprimida".

24 HAMBURGER. Persönalickkeiten. Dorothee Sölle. Disponível em: http://www.hamburgerpersoenlichkeiten.de/hamburgerpersoenlichkeiten/login/person.asp. Acesso em: 20 abr. 2020.

Protestantismo em Revista | São Leopoldo | v. 46, n. 01 | p. 80-97| Jan./jun. 2020

Disponível em: <http://periodicos.est.edu.br/index.php/nepp> 
Embora Sölle não tenha realizado o seu doutorado em teologia, a maioria de suas publicações tratam de questões teológicas. Ela não ocupou uma cadeira de teologia na Alemanha, mas foi professora de teologia sistemática no Union Theological Seminary (Seminário Teológico Unido), em Nova York, entre 1972-1987. Ela como cristã entendeu que a confissão religiosa e a consciência política são inseparáveis. Dorothee Sölle se tornou conhecida por um grande público através de seu envolvimento nos movimentos pela paz, suas aparições/palestras nos dias da igreja na Alemanha ou das leituras de suas próprias poesias em lugares públicos. Ela esteve envolvida em inúmeras iniciativas políticas e ecumênicas e foi co-iniciadora das Orações da Noite Política, que ocorreu em Colônia, entre 1968-1972. Sölle se casou, em um segundo casamento, com o professor de educação religiosa da Universidade de Hamburgo, Fulbert Steffensky. O casal viveu em Hamburgo por muitos anos. Dorothee Sölle morreu em 27 de abril de 2003, em Göppingen, em uma viagem de trabalho.

Em Hamburgo, foi construída em sua homenagem militante a "Casa Dorothee Sölle" 25 , um local para formações, educação política e social, palestras, conferências, músicas, poesias. Nesta casa, encontra-se em uma das paredes, a seguinte citação de Sölle, que foi publicada em 1991, na revista Junge Kirche

\begin{abstract}
Gerechtigkeit ist der Weg zu Gott, den wir finden können. Sie ist der Wille Gottes. Ihretwegen spricht die Bibel so unaufhörlich von den Armen und meint, dass der Reichtum, den wir zwischen uns und den Armen aufhäufen, uns auch Gott verstellt und den Weg zu Gott verbaut. Hat Gott denn etwas mit der Wirtschaftsordnung zu tun? Die Bibel meint: ja, und sie ergreift die Partei der Ärmsten. ${ }^{26}$

A justiça é o caminho para Deus que podemos encontrar. É a vontade de Deus. Por sua causa a Bíblia fala incessantemente dos pobres e significa que a riqueza que acumulamos entre nós e os pobres também obstrui Deus e o caminho para Deus. Deus tem algo a ver com a ordem econômica? A Bíblia diz que sim, e fica do lado dos mais pobres. (Tradução livre de Claudete Beise Ulrich).
\end{abstract}

Durante sua vida atuou como palestrante, escritora, militante professora e pesquisadora em diversas instituições e universidades, tanto na Alemanha, quanto nos Estados Unidos. No entanto, em sua terra natal, Alemanha, obteve reconhecimento acadêmico apenas em seus últimos anos, o que creditamos às suas posições político-sociais bastante revolucionárias para a época. Em 1994, recebeu o título de doutora honoris causa da Universidade de Hamburgo, na Alemanha.

Para a construção de suas reflexões, houve contribuição significativa do que Boaventura de Sousa Santos e Maria Paula Meneses nomearam posteriormente de epistemologias do sul. ${ }^{27}$ Sölle conheceu pessoalmente realidades como a do antigo Vietnam do Norte, no início dos anos 1970; já nos anos 1980, esteve na Nicarágua a convite do Movimento Sandinista; fez várias incursões pela América Latina e teve significativo contato com o MST brasileiro, este que será analisado mais adiante e que representou muito para o

25 DOROTHE-SÖLLE-HAUS HAMBURG. Zentrum für Kirche und Diakonie in Hamburg. Disponível em: <https://www.dorothee-soelle-haus.de/>. Acesso em: 20 maio de 2020. Esta casa se coloca na tradição de Dorothee Sölle na conexão da fé ligada com o engajamento social e político.

26 SÖLLE, Dorothee. Moses, Jesus und Marx - Utopisten auf der Suche nach Gerechtigkeit. Junge Kirche. Eine Zeitschrift europäischer Christen, p. 52, 1991, 52. Disponível em: <https://www.lebenshausalb.de/magazin/007910.html>. Acesso em: 20 abr. 2020.

27 SANTOS, Boaventura de Sousa; MENESES, Maria Paula. (Org.). Epistemologias do Sul. São Paulo: Cortez, 2010, p. 12.

Protestantismo em Revista | São Leopoldo | v. 46, n. 01 | p. 80-97| Jan./jun. 2020

Disponível em: <http://periodicos.est.edu.br/index.php/nepp> 
desenvolvimento da mudança na sua denominação teológica: teologia política para teologia da libertação. ${ }^{28}$ No entanto, é necessário afirmar que as diferentes formas da mística vivida por homens e mulheres na história teve grande influência no seu pensamento, como já citado, destaca-se a mística e teóloga Teresa de Ávila. ${ }^{29}$ Ela também cita no seu livro Mystik und Widerstand, teólogos e escritores latino-americanos e brasileiros como João Cabral de Melo Neto, Leonardo Boff, Helder Câmara, Pedro Casaldáliga, Ernesto Cardenal, apontando para a mística da teologia da libertação. ${ }^{30}$

Dorothee Sölle se reporta a luta de Chico Mendes pelo cuidado da floresta e o seu assassinato. E assim se refere a uma mística da morte dos mártires: "Um outro elemento, que transparece da mística da morte, é uma estranha liberdade, que tudo transforma, ao que denominamos morte. [...] é o que Pedro Casaldáliga diz quando se reporta "ficar nu"." ${ }^{31} \mathrm{~A}$ morte/o assassinato dos que lutam pela igualdade social, o cuidado da terra e da floresta, desnuda o sistema que explora, violenta e mata. Segundo a teóloga

Es gibt Menschen, die das stille Geschrei, das Gott ist, nicht nur hören, sondern es auch hörbar machen als die Musik der Welt, die den Kosmos und die Seele auch heute erfüllt. ${ }^{32}$

Há pessoas que não apenas ouvem os gritos silenciosos de Deus, mas também o tornam audível como a música do mundo que ainda hoje preenche o cosmos e a alma. (Tradução livre de Claudete Beise Ulrich).

Sölle é reconhecida mundialmente como uma das mais destacadas e ao mesmo tempo controversas teólogas protestantes, podendo-se afirmar, ser ela representante de um outro protestantismo, em que, com seus textos teológicos e poesias procura ligar a perspectiva teológica ao cotidiano, às experiências de vida, e de forma especial à luta contra o sofrimento, a pobreza, a discriminação, a opressão. A sua teologia atenta sempre de novo aos gritos e clamores dos sofridos e das injustiças em nosso mundo, que também são os gritos e as dores de Deus.

Politicamente, ela esteve engajada nos movimentos pela paz, contra a construção de usinas nucleares, feminista e nas lutas dos movimentos ecológicos. Além de ter sido uma teóloga política, mística foi feminista. ${ }^{33}$ Ela disse:

28 BOFF, Leonardo; BOFF, Clodovis. Como fazer teologia da libertação. 10. ed. Petropólis: Vozes, 2010, p.37-63. A teologia da libertação se desenvolve na América Latina a partir do final da década de 1960, a partir de espiritualidade engajada na vida dos pobres, utilizando o método ver, julgar e agir.

29 SÖLLE, 2014, p. 122. Tereza De Ávila foi a primeira mulher declarada doutora e professora da Igreja em 1970 pelo Papa Paulo VI.

30 SÖLLE, 2014, p. 365-389.

31 SÖLLE, 2014, p. 376.

32 SÖLLE, 2014, p. 389.

33 SÖLLE, Dorothee. Libertada para a liberdade, condenada ao silêncio: a imagem da mulher no cristianismo. Estudos Teológicos, v. 31, n. 1, p. 76-84, 1991, p. 76. Disponível em: <http://periodicos.est.edu.br/index.php/estudos teologicos/article/view/990>. Acesso em: 20 abril 2020. [...] o projeto da teologia feminista, que rompe com a totalidade da síndrome expressa na fórmula ser humano = homem = máquina. Quem tentar entender o movimento feminista à parte deste pavor existencial, quiçá segundo as categorias burguesas do possuir e fazer carreira ou segundo as categorias pós-modernas de um movimento New Age totalmente livre de temor, irá trivializá-lo e projetar a própria superficialidade para dentro deste novo modo de pensar das mulheres. [...] É exatamente este o sentimento fundamental das

Protestantismo em Revista | São Leopoldo | v. 46, n. 01 | p. 80-97| Jan./jun. 2020

Disponível em: <http://periodicos.est.edu.br/index.php/nepp> 
Não falo sobre algo que Deus poderia evitar ou abolir. Se falamos da dor de Deus, então temos uma outra idéia de Deus que a puramente masculina. Então, Deus é a nossa mãe que chora pelo que fazemos uns aos outros e aos nossos irmãos, aos animais e às plantas. Deus nos consola como o faz uma mãe: ela não consegue tirar a dor como num passe de mágica (se bem que também isso pode acontecer!), mas ela nos segura no colo até conseguirmos levantar outra vez e até tenhamos novas forças. Deus não poderia nos consolar, se Ela não estivesse ligada a nós na dor, se Ela não tivesse essa capacidade maravilhosa e rara de sentir a dor de alguém em seu próprio corpo. Sofrer com, estar aí com. ${ }^{34}$

Suas posições teológicas em favor da justiça social lhe valeram muitas resistências dentro e fora da Igreja. Seu engajamento social foi, entretanto, impulsionador de sua teologia política e libertadora, e esta por sua vez, contribui significativamente para manter a Reforma Protestante em movimento, na construção da liberdade democrática. Construção e continuidade da teologia política podem ser observadas no contexto social, especialmente pela luta pela terra.

\section{O contexto social: a terra, o Movimento dos Trabalhadores Rurais Sem Terra e Dorothee Sölle}

A teologia política e libertadora de Dorothee Sölle foi decisivamente influenciada pelos excluídos sociais, dentre eles os trabalhadores rurais sem terra e especialmente pela luta e a mística do MST. ${ }^{35}$ Ela desenvolveu muito de sua teoria a partir do contato com movimentos socais e ao mesmo tempo esta teoria, a teologia política, da libertação e mística, é hodiernamente instrumento concreto da luta político-social pela terra no Brasil. Para entender o entrelaçamento e o desenvolvimento da obra de Sölle com a luta pela terra e o MST é mister lançar um olhar histórico sobre a história agrária da terra e consequentemente sobre a constituição do MST.

A disparidade em relação à propriedade e ao uso das terras é histórica. Nas sociedades antigas, aos poucos foram se constituindo clãs, que pela força e pela ligação parental, se apropriavam de imensas extensões de terras. E dentro destes clãs, possuir propriedade seguia uma explícita hierarquia. Desde a antiguidade, assim, se constituíram os proprietários e os trabalhadores, à época, em sua maioria escravos.

A estrutura fundiária atual tem ainda muito de suas origens da passagem do Mundo Romano para a Idade Média. Os poderosos da Roma Antiga ruíram o império ao tornarem absoluto o poder sobre suas terras e sobre as pessoas ligadas a essas terras. Importante saber que, em boa parte da Europa, mesmo com o passar dos séculos, os títulos de nobreza e a propriedade dos nobres não foi extinta, ou seja, sua descendência ainda tem em mãos significativa área geográfica, na maioria das vezes, as melhores paragens. $E$ mais que isso, a sociedade latino-americana e brasileira é basicamente oriunda da cultura europeia-ocidental,

mulheres... diante dos homens que têm a obsessão da morte, a qual nada mais é do que o desejo completamente ordinário de dispor totalmente dos objetos e de ter controle sobre aquilo que vive. Pois só é possível querer dispor de tudo quando se percebe tudo que é outro como estando morto. [...] É com este projeto da morte que mulheres hoje rompem. Elas descobrem a "sororidade" e novas formas de relacionamento recíproco [...].

34 SÖLLE, Dorothee. Deve haver algo mais: reflexões sobre Deus. Petrópolis: Vozes, 1999, p. 63.

35 SÖLLE, 2014, p. 376.

Protestantismo em Revista | São Leopoldo | v. 46, n. 01 | p. 80-97| Jan./jun. 2020

Disponível em: <http://periodicos.est.edu.br/index.php/nepp> 
reproduzindo também a disparidade fundiária e a consequente continuidade da histórica exclusão camponesa.

A concentração das terras é assim, um problema histórico na América Latina e especialmente no Brasil. Desde o sistema colonial, as maiores extensões e as terras mais produtivas pertencem apenas a alguns poucos grandes fazendeiros. Terra não pertence para aqueles que nela trabalham. ${ }^{36}$ Para Argemiro Jacob Brum, a terra serviu historicamente "de base de poder para uns poucos senhores sobre milhares e milhões de escravos, parceiros, meeiros, arrendatários e posseiros Sem Terra" ${ }^{37}$ De acordo com Caio Prado Junior, há por um lado as grandes plantações, com riqueza, prosperidade e grande atividade econômica e por outro, o não atendimento à necessidade mais básica da grande maioria da população - a fome. ${ }^{38} \mathrm{Na}$ prática, solo de qualidade nas mãos dos camponeses é a exceção e não a regra. ${ }^{39}$ Para a maioria da população isso significa viver às margens. "Às margens das fazendas, às margens dos direitos mais elementares, às margens da sociedade". ${ }^{40} \mathrm{Na}$ prática, a pobreza, seja no campo, seja nas favelas urbanas.

A partir dos anos 1960 essa problemática foi agravada. Com a modernização capitalista da agricultura houve significativo aumento da concentração das terras. Essa modernização conservadora do campo apresentou também profundas mudanças no processo produtivo, entre outras, a mecanização, com a qual mais camponeses e camponesas perderam seu trabalho nas fazendas, que, aliás, já era precário. Para Schönardie, isso trouxe consigo mudanças profundas para a agricultura brasileira. A favelização e a concentração de acampados à beira das rodovias foi agravada. É sabido também que a indústria brasileira não estava configurada para absorver a mão-de-obra dos/as 'sobrantes' do campo. ${ }^{41}$

Essa difícil realidade dos seres humanos foi cada vez mais percebida por setores progressivos da Igreja. Teólogos e teólogas comprometidos/as com a necessidade social, especialmente com a precária situação de camponesas e camponeses, desenvolveram a teologia da libertação. Na prática, organizaram as Comunidades Eclesiais de Base, que consistiam em pequenos grupos de pessoas, em suas realidades, e que discutiam, a partir de valores cristãos, a sua realidade social, os seus problemas. Central na teologia da libertação era assim perceber a alienação à que estavam aprisionados e se libertar desta alienação. Podese afirmar que as Comunidades Eclesiais de Base constituíram assim um processo educativo genuíno. De acordo com Maria Clara Bingemer

Os teólogos da libertação mais renomados enfatizaram a tremenda interpelação que a existência da pobreza, concebida deste modo, representa para a humanidade, situando esse problema no centro do pensamento teológico. Eles se esforçaram para descobrir as causas da pobreza e os meios para combatê-la. Eles promoveram a criação de Comunidades Eclesiais de Base que, por meio da leitura da Bíblia,

36 SCHÖNARDIE, 2013, p. 134.

37 BRUM, Argemiro Jacob. Modernização da Agricultura. Trigo e soja. Petrópolis: Vozes, 1988, p. 52.

38 PRADO JÚNIOR, Caio. História econômica do Brasil. 2. ed. São Paulo: Brasiliense, 1949, p. 52.

39 FEDER, Ernest. Agrarstruktur und Unterentwicklung in Lateinamerika. Frankfurt am Main: Europäische Verlagsanstalt - EVA, 1973, p. 77.

40 SCHÖNARDIE, 2014, p. 88.

41 SCHÖNARDIE, Paulo Alfredo. Bäuerliche Landwirtschaft im Süden Brasiliens. Historische, theoretische und empirische Studie zu Ernährungssouveränität, Modernisierung, Wiederbelebung und Staatsfunktion. München: Oekom, 2013, p. 203.

Protestantismo em Revista | São Leopoldo | v. 46, n. 01 | p. 80-97| Jan./jun. 2020

Disponível em: <http://periodicos.est.edu.br/index.php/nepp> 
ajudaram os pobres a ver sua situação mais nitidamente e a tomar as decisões necessárias para transformá-la. ${ }^{42}$

A Igreja começou a se perceber como Igreja dos pobres. As Comunidades Eclesiais de Base foram oficialmente reconhecidas e apoiadas com a constituição da Comissão Pastoral da Terra (CPT), entre vários outros movimentos. ${ }^{43} \mathrm{O}$ contexto educativo construído, acreditamos ter levado a teologia da libertação ao seu objetivo, ou seja, a libertação do ideário, para, com autonomia, os sujeitos agirem em sua história.

A organização dos camponeses e das camponesas Sem Terra foi uma consequência, o que entendemos ir além da teologia da libertação. Neste momento, começou a ação política, que logo se materializou no MST e nas suas ações. A Igreja e seus representantes, contudo, sempre continuaram presentes, tanto que a cruz e sua simbologia sempre acompanharam os Sem Terra em suas ações.

Nessa conjuntura em que Sölle se insere, reconstrói sua reflexão e ao mesmo tempo contribui com o movimento de luta dos MST. Além da teologia da libertação, necessitamos falar em teologia política e mística com a qual, e pelo exemplo da luta pela terra, se vai em busca de objetivos palpáveis, ou seja, a cidadania, o direito à vida dos/as que estão às margens. E isto que Sölle percebe de forma primordial, adaptando a linguagem teológica à luta social concreta, reformando esta linguagem pelo contexto de necessidade humana real. Ela percebe a força da mística do Movimento dos Sem Terra ${ }^{44}$, o que também Walter Marschner reflete, dizendo

\begin{abstract}
a redescoberta da experiência mística pelos movimentos sociais traz um potencial revelador: ela mostra nosso papel no topo da sociedade: nosso consumo, nosso modo de vida nos faz inimigos da terra, uma sociedade global onde 1 terço vive às expensas de $2 / 3$ da humanidade. Por isso somos inimigos do céu sobre nós e inimigos de nós mesmos. A mística nestes tempos só pode ser de resistência, senão não é. $A$ atitude mística hoje é capaz de proclamar uma outra realidade, é capaz de dizer... "um outro mundo é possível". ${ }^{45}$
\end{abstract}

Sölle nos ensinou que não basta apenas entender a realidade social, mas é necessário denunciar as estruturas de morte a atuar nos movimentos para uma transformação. Para ela deve haver algo mais, e este algo mais é o fato de que após entender a realidade e sair da condição de oprimido ${ }^{46}$, também a ação teológica precisa ir em direção objetivando mudança no mundo e no caso dos Sem Terra, na ação destes em direção à conquista da terra e direitos. Assim Sölle constituiu a sua práxis social, que se mostra na sua teologia política, mística e feminista. Ela assim se expressou:

No mundo é frio demais para pensarmos que podemos viver sem esse manto. A graça nos aquece, mas ao mesmo tempo, nos ajuda a participarmos e tricotarmos o manto de Deus. [...] Nós todos somos participantes de Deus. Deus nos consola e nós

42 BINGEMER, Maria Clara. Teologia Latino-americana: raízes e ramos. Rio de Janeiro: Vozes, 2017, p. 63.

43 BOFF; BOFF, 2010, p. 102.

44 SÖLLE, 2014, p. 376.

45 MARSCHNER, Walter. A mística da terra e a educação popular. IX Congreso Argentino de Antropología Social. Facultad de Humanidades y Ciencias Sociales. Posadas: Universidad Nacional de Misiones, 2008, p. 9-10. Disponível em: http://cdsa.aacademica.org/000-080/158.pdf. Acesso em: 10 abr. 2020.

46 FREIRE, 1987, p. 16-32.

Protestantismo em Revista | São Leopoldo | v. 46, n. 01 | p. 80-97| Jan./jun. 2020

Disponível em: <http://periodicos.est.edu.br/index.php/nepp> 
preparamos o caminho de Deus. A voz de Deus nos chama e nós respondemos. O Espírito de Deus quer nos tornar corajosos e aptos à verdade. Deus quer nascer em nós. ${ }^{47}$

Ela também criou o termo "Christus fascismus" (cristofascismo). Um conceito que aponta para a aliança entre o cristianismo, o nacionalismo e o capitalismo que andam de mãos dadas com a exploração e a destruição da natureza, de grupos humanos minoritários e impõe somente uma forma de pensar e viver. Em sua análise, Sölle identifica três elementos-chave que sustentam seu conceito de "cristofascismo": 1. A cimentação da teologia cristã com a ideologia capitalista e o nacionalismo (incluindo a superioridade moral), 2. Uma ética de trabalho e 3. Papéis familiares tradicionais que policiam as mulheres em particular. Inerentes a esses elementos estão as manifestações de nacionalismo, militarismo e racismo por parte da liderança governamental e também entre os cristãos. Neste sistema cristofascista, a imprensa livre é ofuscada pela censura e a segurança nacional é mantida como doutrina sagrada. Temas de justiça e solidariedade são negligenciados. ${ }^{48}$ Ela denuncia o uso ideológico do cristianismo a favor do capitalismo explorador da terra que se afirma no sistema patriarcal ${ }^{49}$, racista, sexista, militar e que não respeita a diversidade e por isso violenta e mata as populações não brancas, as mulheres, a natureza. Ela denuncia a construção patriarcal do mundo, que se coloca contra a criação, o tecido da vida..$^{50}$

Da mesma maneira, ela construiu o instrumentário teórico para a concreta ação na luta pela terra, ela também aplicou sua teoria na luta político-social no movimento ecológico e para as conquistas no movimento feminista. Ao fazer isto ela está sendo revolucionária, colocando-se dentro do movimento contínuo da Reforma Protestante. A “Igreja e a teologia passam a ser mais que a 'palavra' que liberta da alienação, passam a ser instrumento concreto da luta por melhorias sociais". ${ }^{51}$ A teologia política, mística, feminista traz consigo o processo da práxis educativa popular.

\section{A teologia política, mística, feminista como processo educativo popular}

47 SÖLLE, 1999, p. 16; p. 109.

48 SÖLLE, Dorothee. Das Fenster der Verwundbarkeit: Theologisch-politische Texte. 1. Auflage. Stuttgart: Kreuz Velag, 1987, p.158-167.

49 SÖLLE, 1991, p. 76. "O patriarcado apoderou-se há muito da criação e do fim do mundo, do Alfa e do Ômega, incorporando-os ao seu império: o poder, muitas vezes imediatamente reivindicado como onipotência, é o valor central; a sujeição da natureza e da mulher (conceitos intercambiáveis em muitos textos) é a tarefa; segregação, demarcação, apartheid, repressão e violência aberta são os métodos empregados pelo homem branco contra tudo que é definido como diferente. A cisão do átomo e de núcleos celulares realmente mudou tudo; somente o pensamento patriarcal permaneceu fixado a seus valores."

50 SÖLLE, 1991, p. 76. "Com isso pretendo chamar a atenção para a tendência necrofílica (sic.) da construção patriarcal do mundo, cada vez mais visível nos dias de hoje. O mais importante meio de produção dos seres humanos, a ciência, é movido por uma profunda hostilidade à criação. A exigência de dominar a vida, de pôr de lado todos os limites que continuam a resistir à investigação perscrutadora e de fazer tudo que pode ser feito é hoje mais visível do que nunca. Com isso não quero dizer que todos os pesquisadores estejam possuídos pela vontade de poder, mas que o sistema patriarcal da ciência ocidental hoje ameaça, como jamais o fez antes, a criação, o tecido da vida."

51 STRECK, Danilo R.; PITANO, Sandro de Castro; MORETTI, Cheron Zanini; SANTOS, Karine; LEMES, Marilene Alves; PAULO, Fernanda dos Santos. Educação popular e docência. São Paulo: Cortez, 2014. p. 90.

Protestantismo em Revista | São Leopoldo | v. 46, n. 01 | p. 80-97| Jan./jun. 2020

Disponível em: <http://periodicos.est.edu.br/index.php/nepp> 
Quando as pessoas, pela sua ação, como nas organizações e movimentos, dentre os quais os da luta pela terra, se tornam protagonistas, sujeitos de sua história, elas vivenciam um processo educativo privilegiado de práxis em seu contexto social. A educação popular é uma concepção de educação latino-americana. Ela "é uma prática educativa e uma proposta pedagógica que se situa dentro e diante dos conflitos históricos das sociedades latinoamericanas". ${ }^{52} \mathrm{Em}$ sua fase de desenvolvimento mais recente traz consigo "a presença da teologia [...] especialmente da vertente social cristã, [que] se percebe por meio do pensamento de Paulo Freire" ${ }^{53}$ Antes de mais nada, integra aspectos éticos, políticos e filosóficos que contribuem para a teologia da libertação.

\begin{abstract}
A inspiração cristã se explicita pela tese freiriana de que homens e mulheres são vocacionados para a liberdade, núcleo central do Evangelho. A inconclusão humana, a dimensão dialógica e relacional da existência e a perspectiva dos oprimidos, marcantes em Freire e que encontram fundamentos no texto bíblico, são princípios assumidos pela educação popular. ${ }^{54}$
\end{abstract}

Assim como a perspectiva da teologia política e feminista de Sölle reconhece e tem seu ponto de partida nos sujeitos oprimidos em sua luta pela libertação, é preciso em primeiro lugar, reconhecer os/as oprimidos/as para perceber que, eles/as em seu processo de libertação, que é educativo, constroem protagonismo histórico. Neste reconhecimento está situada a vocação da educação popular como forma de resistência ${ }^{55}$, como a resistência transformadora, vivenciada pelos Sem Terra. A numerosa existência de oprimidos, de acordo com Freire e a luta destes em comunhão com vistas a sair da opressão ${ }^{56}$, faz com que a educação popular e o seu entrelaçamento com teólogas e teólogos comprometidos politicamente, emerja "como um movimento de trabalho político com as classes populares através da educação". ${ }^{57} \mathrm{~A}$ concepção pedagógica popular tem, desta maneira, profundas raízes na sua "alta sensibilidade aos contextos políticos, sociais e culturais" 58 , estando objetiva a intencionalidade política emancipadora. ${ }^{59} \mathrm{Nela}$, está presente um processo de libertação via conscientização política ${ }^{60}$, o que pela teologia política, feminista, crítica e libertadora de Sölle se dá pela ação política e mística embasada pelos valores do Evangelho, isto é, a proclamação da vida. Estes são percebidos no núcleo da educação popular. Este se dá

a partir de uma crítica indignada da ordem social dominante e a partir da identificação com visões de futuro alternativas, busca contribuir para a constituição de diversos setores subalternos como sujeitos de transformação, incidindo em

52 STRECK et al., 2014, p. 21.

53 STRECK et al., 2014, p. 71.

54 STRECK et al., 2014, p. 71.

55 BRANDÃO, Carlos Rodrigues. Prefácio. Cinquenta e um anos depois. In: STRECK, Danilo R.; ESTEBAN, Maria Teresa. (Org.). Educação popular. Lugar de construção social coletiva. Petrópolis: Vozes, 2013, p. 12.

56 FREIRE, 1987, p. 29-32.

57 BRANDÃO, Carlos Rodrigues. O que é a educação popular? São Paulo: Brasiliense, 2006, p. 75.

58 TORRES, Alfonso A educação popular como prática política e pedagógica emancipatória. In: STRECK, Danilo R.; ESTEBAN, Maria Teresa. (Org.). Educação popular. Lugar de construção social coletiva. Petrópolis: Vozes, 2013, p. 19.

59 TORRES. Alfonso. La educación popular. Trayectoria y actualidad. Bogotá: El Buho, 2008, p. 13.

60 STRECK et al., 2014, p. 32.

Protestantismo em Revista | São Leopoldo | v. 46, n. 01 | p. 80-97| Jan./jun. 2020

Disponível em: <http://periodicos.est.edu.br/index.php/nepp> 
diferentes âmbitos de sua subjetividade, mediante estratégias pedagógicas dialogais, problematizadoras, criativas e participativas. ${ }^{61}$

A educação popular é assim, protagonizada pelos oprimidos, que em sua ação, se libertam a partir das muitas margens ${ }^{62}$, constituindo territórios de resistência ${ }^{63}$, em que 'outros sujeitos'64, ou seja, Sem Terra, Mulheres, Negras/os, Quilombolas, Indígenas, Pomeranas/os entre outros grupos assumam sua condição, transformando o sofrimento em entendimento/conhecimento, resistência e ação transformadora. ${ }^{65} \mathrm{~A}$ educação popular é assim "uma prática educativa que se propõe a ser diferenciada, isto é, compromissada com os interesses e a emancipação das classes subalternas. ${ }^{66}$. Por ela se buscam a constituição de sujeitos populares "capazes de serem os construtores de sua própria história de libertação"67. Conceição Paludo destaca a estreita relação entre o político e o pedagógico na educação popular para a emancipação humana. ${ }^{68} \mathrm{E}$ é isto que Sölle percebe pela palavra do Evangelho, por isso pode-se afirmar que sua interpretação pela ação, pela tomada de posição, é libertadora e emancipadora. Portanto, o Evangelho proclamado necessita tornar-se ação de cuidado da terra e das pessoas que nela vivem e trabalham.

A práxis, a ação e a reflexão, características do ser humano, estão assim, na base da educação popular e ao mesmo tempo da teologia política, mística e feminista. O humano, "atuando, transforma; transformando, cria uma realidade que, por sua vez, 'envolvendo-o', condiciona sua forma de atuar" ${ }^{69}$. Sölle insere a teologia política, que ela foi assumindo como mística, feminista e libertadora na perspectiva emancipadora e respeitadora, da terra, da natureza, em seus escritos e poesias. Aqui se encontram também pontos de relação com o desenvolvimento do movimento social do MST.

\section{Algumas Considerações Finais}

Acumulamos e vivenciamos cinco séculos de reformas protestantes, e afirmando esta continuidade histórica, reconhecemos que reformadores e reformadoras contribuíram com o ideário que buscava transformações da sociedade. É dentro deste contexto que Dorothee Sölle avança com sua teologia política, mística, feminista crítica e libertadora percebida aqui como uma forma de reformar o pensamento/conhecimento e a ação teológica

61 TORRES, 2013, p. 19.

62 EGGERT, Edla. As muitas margens da educação popular. In: STRECK, Danilo R.; ESTEBAN, Maria Teresa. (Org.). Educação popular. Lugar de construção social coletiva. Petrópolis: Vozes, 2013, p. 143-150.

63 STRECK, Danilo R. Entre emancipação e regulação. (Des)encontros entre educação popular e movimentos sociais. In: Revista Brasileira de Educação. v. 15 n. 44, p. 300-409, 2010, p. 301. Disponível em: <https://www.scielo.br/pdf/rbedu/v15n44/v15n44a07.pdf>. Acesso em: 25 abr. 2020.

64 ARROYO, Miguel G. Outros sujeitos, outras pedagogias. Petrópolis: Vozes, 2014.

65 PULEO, Alicia H. Anjos do Ecossistema? In: FARIA, Nalu; MORENO, Renata (Org.). Análises feministas: outro olhar sobre economia e ecologia. São Paulo: SOF, 2012, p. 46-47.

66 PALUDO, Conceição. Educação popular em busca de alternativas. Uma leitura desde o campo democrático e popular. Porto Alegre: Tomo Editorial/Camp, 2001, p. 82.

67 PALUDO, 2001, p. 99.

68 PALUDO, Conceição. Educação popular como resistência e emancipação humana. Cad. Cedes, v. 35, n. 96, p. 219-238, 2015, p. 220. Disponível em: <https://www.scielo.br/pdf/ccedes/v35n96/1678-7110-ccedes-35-9600219.pdf>. Acesso em: 20 maio 2020.

69 FREIRE, Paulo. Extensão ou comunicação? Rio de Janeiro: Paz e Terra, 1992, p. 28.

Protestantismo em Revista | São Leopoldo | v. 46, n. 01 | p. 80-97| Jan./jun. 2020

Disponível em: <http://periodicos.est.edu.br/index.php/nepp> 
As mudanças tendem a vir de contextos sociais adversos, contextos de premência humana. Assim como na época de Lutero e de Müntzer, a conjuntura histórica e presente da problemática fundiária esfacela em brumas grande parcela da população, sobretudo a rural. $E$ a reação a esta difícil realidade é base para o pensamento teológico e para o Evangelho, para os valores cristãos. A partir dessa realidade, já compreendida no movimento, que Sölle, embasada na teologia, propõe a ação política, construindo um arcabouço em que prega teologicamente caminhos sociais construtivos em que os sujeitos das margens de forma autônoma reconstroem suas vidas. Ela denunciou o cristianismo usado para fortalecer o sistema capitalista destruidor da natureza e de populações pobres.

Este espaço de ação política passa a ser educativo na medida em que é vivenciado de forma consciente e ao mesmo tempo pela práxis, configurando processos de educação popular. Os ensinamentos de Sölle são desta forma, multiplicados, contribuindo por um lado para fortalecer os movimentos sociais e ao mesmo tempo em que vivenciados, a partir da mística e de novas relações entre homens e mulheres, apontam para a construção de uma sociedade igualitária e justa. Mas é fundamental perceber que Sölle construiu sua teoria através da prática social de vida dos seres humanos e de sua própria base vivencial. Ela própria, em primeiro lugar viveu a realidade. Neste sentido, ela nos convida, assim, a fazer o mesmo. Agir teologicamente pela perspectiva da teologia política, mística, feminista e libertadora significa assumir como cristão e cristã, o apoio e a real intervenção para a melhora das condições de vida dos/as oprimidos/as, excluídos/as. E em uma sociedade, com um modo de produção excludente, como a que vivemos, isso é revolucionário. Ter essa coragem é efetivamente transformador.

Dorothee Sölle, uma grande teóloga, que através dos seus escritos, continua a nos dizer que a teologia não é neutra. A teologia tem lado: o lado dos/as pobres, espoliados pelo capital, que quer se apropriar do cristianismo. Por isso, toda denúncia é necessária em relação ao Critofascismo tão presente em nossos dias. É necessário ouvir o grito de Deus que se mostra no grito de todos e todas que sofrem violência, exploração e morte e naqueles/as que se erguem corajosamente contra o sistema que destrói, violenta e mata. Ouçamos os clamores e gritos de Deus, que se expressa na natureza e nas pessoas que estão nas margens. Teresa de Ávila, inspiradora de Dorothee de Sölle, também quer nos inspirar e fortalecer com as suas palavras: Deus só tem as nossas mãos para agir neste mundo.

\section{Referências}

ARROYO, Miguel G. Outros sujeitos, outras pedagogias. Petrópolis: Vozes, 2014.

BINGEMER, Maria Clara. Teologia Latino-americana: raízes e ramos. Rio de Janeiro: Vozes, 2017.

BOFF, Leonardo; BOFF, Clodovis. Como fazer teologia da libertação. 10. ed. Petropólis: Vozes, 2010.

BRANDÃO, Carlos Rodrigues. O que é a educação popular? São Paulo: Brasiliense, 2006.

BRANDÃO, Carlos Rodrigues. Prefácio. Cinquenta e um anos depois. In: STRECK, Danilo R.; ESTEBAN, Maria Teresa. (Org.) Educação popular. Lugar de construção social coletiva. Petrópolis: Vozes, 2013.

BRUM, Argemiro Jacob. Modernização da Agricultura. Trigo e soja. Petrópolis: Vozes, 1988.

Protestantismo em Revista | São Leopoldo | v. 46, n. 01 | p. 80-97| Jan./jun. 2020

Disponível em: <http://periodicos.est.edu.br/index.php/nepp> 
DOROTHE-SÖLLE-HAUS HAMBURG. Zentrum für Kirche und Diakonie in Hamburg. Disponível em: <https://www.dorothee-soelle-haus.de/>. Acesso em: 20 maio de 2020.

EGGERT, Edla. As muitas margens da educação popular. In: STRECK, Danilo R.; ESTEBAN, Maria Teresa. (Org.). Educação popular. Lugar de construção social coletiva. Petrópolis: Vozes, 2013. p. $143-150$.

EGGERT. Edla. Educação popular e teologia das margens. São Leopoldo: Sinodal, 2003.

ENGELS, Friedrich. As guerras camponesas na Alemanha. Lisboa; São Paulo: Editorial Presença; Martins Fontes, 1975.

FEDER, Ernest. Agrarstruktur und Unterentwicklung in Lateinamerika. Frankfurt am Main: Europäische Verlagsanstalt - EVA, 1973.

FREIRE, Paulo. Extensão ou comunicação? Rio de Janeiro: Paz e Terra, 1992.

FREIRE, Paulo. Pedagogia do Oprimido. Rio de Janeiro: Paz e Terra, 1987.

GONÇALVES, Paulo Sérgio Lopes.Nova Teologia Política: memoria passionis e mística de olhos abertos. Cultura Teológica, n. 93, p. 272-301, 2019. Disponível em: <https://revistas.pucsp.br/culturateo/article/view/rct.i93.42770>. Acesso em: 20 maio 2020.

HAMBURGER. Persönalickkeiten. Dorothee Sölle. Disponível em: http://www.hamburgerpersoenlichkeiten.de/hamburgerpersoenlichkeiten/login/person.asp . Acesso em: 20 abr. 2020.

KUZMA, Cesar. O teólogo Jürgen Moltmann e o seu caminhar teológico realizado na esperança. Acenos teo-biográficos. Atualidade Teológica, Ano XVII n. 43, p. 15-38, 2013.

LUTERO, Martinho. Exortação à paz: Resposta aos Doze Artigos do Campesinato da Suábia 1525. In: LUTERO, Martinho. Obras selecionadas. São Leopoldo: Sinodal, Porto Alegre: Concórdia, 1996. v. 6, p. 304-329.

LUTERO, Martinho. Exortação à paz: Resposta aos Doze Artigos do Campesinato da Suábia 1525. Adendo: Contra as Hordas Sateadoras e Assassinas dos Camponeses 1525. In: LUTERO, Martinho. Obras selecionadas. São Leopoldo: Sinodal, Porto Alegre: Concórdia, 1996. v. 6, p. 330-336.

LUTERO, Martinho. Explicações do Debate sobre o valor das indulgências. In: LUTERO, Martinho. Obras Selecionadas. Os primórdios escritos de 1517 a 1519. v. 1 São Leopoldo: Sinodal; Porto Alegre: Concórdia, 1987.

MARSCHNER, Walter. A mística da terra e a educação popular. IX Congreso Argentino de Antropología Social. Facultad de Humanidades y Ciencias Sociales. Posadas: Universidad Nacional de Misiones, 2008. Disponível em: http://cdsa.aacademica.org/000-080/158.pdf. Acesso em: 10 abr. 2020.

METZ, Johann Baptist. Teologia Política. Trad. Luis Alberto De Boni. Porto Alegre: Escola Superior de Teologia São Lourenço de Brindes; Caxias do Sul: Universidade de Caxias do Sul, 1976.

MOLTMANN, Jürgen. Teologia da esperança: estudos sobre os fundamentos e as consequências de uma escatologia cristã. 3 São Paulo: Teológica, Loyola, 2005.

Protestantismo em Revista | São Leopoldo | v. 46, n. 01 | p. 80-97| Jan./jun. 2020

Disponível em: <http://periodicos.est.edu.br/index.php/nepp> 
OS DOZE ARTIGOS DO CAMPESINATO DA SUÁBIA (1525). Traduzido do alemão por WIRTH, Lauri E. a partir da versão publicada em OBERMANN, Heiko A. (Comp.). Die Kirche im Zeitalter der Reformation: Kirchen-und Theologiegeschichte in Quellen, Band 3, 2 Aufl. NeukirchenVluyn, 1985, documento no 64, p. 127-129. In. ZWETSCH, Roberto (Org.). Resgatando a Radicalidade da Reforma Protestante (1517-2017). São Leopoldo: Centro de Estudos Bíblicos - CEBI, 2019. p. 98-103.

PALUDO, Conceição. Educação popular como resistência e emancipação humana. Cad. Cedes, v. $35, \quad$ n. 96, p. 219-238, 2015. p. 220. Disponível em: <https://www.scielo.br/pdf/ccedes/v35n96/1678-7110-ccedes-35-96-00219.pdf>. Acesso em: 20 maio 2020.

PALUDO, Conceição. Educação popular em busca de alternativas. Uma leitura desde o campo democrático e popular. Porto Alegre: Tomo Editorial/Camp, 2001.

PRADO JÚNIOR, Caio. História econômica do Brasil. 2. ed. São Paulo: Brasiliense, 1949.

PULEO, Alicia H. Anjos do Ecossistema? In: FARIA, Nalu; MORENO, Renata (Org.). Análises feministas: outro olhar sobre economia e ecologia. São Paulo: SOF, 2012. p. 29-50.

RENDERS, Helmut. Um testemunho de esperança como summa theologicae de uma vida. Resenha do livro Tradução: Haroldo Reimer e Levy da Costa Bastos. São Bernardo do Campo, SP: Editeo, 2008. Estudos de Religião MOLTMANN, Jürgen. Vida, esperança e justiça: um testamento teológico para a América Latina., v. 23, n. 36, citação n. 13, p. 280, 2009. Disponível em: <https://www.metodista.br/revistas/revistasims/index.php/ER/issue/view/75>. Acesso em: 20 maio 2020.

SANTOS, Boaventura de Sousa; MENESES, Maria Paula. Epistemologias do Sul. São Paulo: Cortez, 2010.

SATHLER-ROSA, Ronaldo. Religiões, contexto e política: uma aproximação teológico-cultural. E-legis, n. 13, p. 7-20, 2014. Disponível em: <e-legis.camara.leg.br> e-legis > article > download>. Acesso em: 22 abr. 2020.

SCHÖNARDIE, P. A. Die Landlosenbewegung (MST) Brasiliens und die politische Theologie von Dorothee Sölle. In: ULRICH, Claudete Beise; ANDREE, Uta. (Org.). (Theologische Impulse der Missionsakademie - Tima. Inspiration für eine Theologie des Lebens. Die Theologie von Dorothee Sölle im Licht der Befreiungstheologie. Hamburg: Missionsakademie an der Universität Hamburg, 2014. p. 87-92.

SCHÖNARDIE, Paulo Alfredo. Bäuerliche Landwirtschaft im Süden Brasiliens. Historische, theoretische und empirische Studie zu Ernährungssouveränität, Modernisierung, Wiederbelebung und Staatsfunktion. München: Oekom, 2013.

SÖLLE, Dorothee. Das Fenster der Verwundbarkeit: Theologisch-politische Texte. 1. Auflage. Stuttgart: Kreuz Velag, 1987.

SÖLLE, Dorothee. Deve haver algo mais. Reflexões sobre Deus. Petrópolis: Vozes, 1999.

SÖLLE, Dorothee. Libertada para a liberdade, condenada ao silêncio: a imagem da mulher no cristianismo. Estudos Teológicos, v. 31, n. 1, p. 76-84, 1991, p. 76. Disponível em: http://periodicos.est.edu.br/index.php/estudos_teologicos/article/view/990. Acesso em: 20 abril 2020.

Protestantismo em Revista | São Leopoldo | v. 46, n. 01 | p. 80-97| Jan./jun. 2020

Disponível em: <http://periodicos.est.edu.br/index.php/nepp> 
SÖLLE, Dorothee. Mystik und Widerstand: „Du stilles Geschrei“. Mit einer Einleitung von Fulbert Steffensky. Freiburg im Breisgau, 2014.

SÖLLE, Dorothee. Sofrimento. Petrópolis: Vozes, 1996.

STRECK, Danilo R. Entre emancipação e regulação. (Des)encontros entre educação popular e movimentos sociais. In: Revista Brasileira de Educação. v. 15 n. 44, p. 300-409, 2010. p.301. Disponível em: <https://www.scielo.br/pdf/rbedu/v15n44/v15n44a07.pdf>. Acesso em: 25 abr. 2020.

STRECK, Danilo R.; PITANO, Sandro de Castro; MORETTI, Cheron Zanini.; SANTOS, Karine.; LEMES, Marilene Alves; PAULO, Fernanda dos Santos. Educação popular e docência. São Paulo: Cortez, 2014.

TORRES, Alfonso. A educação popular como prática política e pedagógica emancipatória. In: STRECK, Danilo R.; ESTEBAN, Maria Teresa. (Org.). Educação popular. Lugar de construção social coletiva. Petrópolis: Vozes, 2013.

TORRES. Alfonso. La educación popular. Trayectoria y actualidad. Bogotá: El Buho, 2008.

ULRICH, Claudete Beise; ANDRÉE, Uta. (Org.). (Theologische Impulse der Missionsakademie Tima). Inspiration für eine Theologie des Lebens. Die Theologie von Dorothee Sölle im Licht der Befreiungstheologie. Hamburg: Missionsakademie an der Universität Hamburg, 2014.

ULRICH, Claudete Beise; BRAKEMEIER, Ruthild. Mulheres reformadoras fazendo Diaconia e Direitos. In: KUSS, Cibele (Org.). Fé, justiça de gênero e incidência pública: 500 anos da reforma e diaconia transformadora. Porto Alegre: Fundação Luterana de Diaconia, 2017.

ULRICH, Claudete Beise; DALFERTH, Heloisa Gralow. (Org.). Mulheres no Movimento da Reforma. São Leopoldo: Sinodal, 2017.

WIND, Renate. Grenzenlos glücklich - absolut furchtlos - immer in Schwierigkeiten. München: Gütersloh, 2013.

WIRTH, Lauri Emilio. Antecedentes Populares da Reforma Protestante: Para entender os doze artigos do Campesinato da Suábia. In: ZWETSCH, Roberto (Org.). Resgatando a Radicalidade da Reforma Protestante (1517-2017). São Leopoldo: Centro de Estudos Bíblicos - CEBI, 2019. p. 104-112. 